\title{
Purified Human Plasma Kallikrein Aggregates
}

\section{Human Blood Neutrophils}

\author{
Marc Schapira, Eliane Despland, Cheryl F. Scott, laurence A. Boxer, and \\ Robert W. Colman, Division de Rhumatologie, Hôpital Cantonal \\ Universitaire, 1211 Genève 4, Switzerland; Thrombosis Research Center, \\ Temple University School of Medicine, Philadelphia, Pennsylvania 19140; \\ Division of Pediatric Hematology-Oncology, Indiana University School of \\ Medicine, Indianapolis, Indiana 46223.
}

A B S TRACT Exposure of human blood polymorphonuclear leukocytes (PMN) to purified active plasma kallikrein resulted in PMN aggregation when kallikrein was present at concentrations ranging from 0.4 to $0.6 \mathrm{U} / \mathrm{ml}(0.18-0.27 \mu \mathrm{M})$. Kallikrein-induced PMN aggregation was not mediated through C5-derived peptides, because identical responses were observed whether or not kallikrein had been preincubated with an antibody to C5. Moreover, kallikrein was specific for aggregating PMN, because no aggregation was observed with Factor XII active fragments $(23 \mathrm{nM})$, Factor XIa $(0.6 \mathrm{U} / \mathrm{ml}$ or $15 \mathrm{nM})$, thrombin $(1.6 \mu \mathrm{M})$, plas$\min (2 \mu \mathrm{M})$, porcine pancreatic elastase $(2 \mu \mathrm{M})$, bovine pancreatic chymotrypsin $(2 \mu \mathrm{M})$, or bradykinin $(1 \mu \mathrm{M})$. Bovine pancreatic trypsin $(2 \mu \mathrm{M})$ aggregated $\mathrm{PMN}$, but to a lesser extent than kallikrein $(0.18 \mu \mathrm{M})$. Kallikrein was a potent aggregant agent for PMN because similar responses were observed with kallikrein $(0.5$ $\mathrm{U} / \mathrm{ml}$ or $0.23 \mu \mathrm{M})$ and an optimal dose $(0.2 \mu \mathrm{M})$ of $N$ formyl-methionyl-leucyl-phenylalanine. In addition, PMN incubation with kallikrein resulted in stimulation of their oxidative metabolism as assessed by an increased oxygen uptake. Neutropenia and leukostasis observed in diseases associated with activation of the

This work was presented in part at the Twenty-third Annual Meeting of the American Society of Hematology, San Antonio, TX, 5-8 December 1981 and was reported in abstract form in 1981. Blood. 58(Suppl. 1): 77A.

Received for publication 18 January 1982 and in revised form 22 February 1982. contact phase system may be the result of PMN aggregation by plasma kallikrein.

\section{INTRODUCTION}

During the contact activation of blood coagulation, fibrinolysis, and kinin generation, human plasma prekallikrein undergoes a limited proteolytic cleavage, resulting in the formation of plasma kallikrein, a serine protease (1). Once formed, plasma kallikrein activates Factor XII to Factor XIIa, plasminogen to plasmin, and liberates bradykinin from high molecular weight kininogen (1). In addition, partially purified human plasma kallikrein preparations have been reported to enhance blood polymorphonuclear leukocyte $(\mathrm{PMN})^{1}$ chemotaxis (2) and aerobic glucose metabolism (3). However, these conclusions were recently challenged by the observation that purified rabbit kallikrein was not directly chemotactic for rabbit PMN (4). In this latter report, kallikrein-associated chemotactic activity was observed only after rabbit plasma kallikrein had been incubated with rabbit $\mathrm{C} 5$, thereby generating a C5a-like peptide (4).

In this communication, we describe the effect of highly purified human plasma kallikrein on human

\footnotetext{
${ }^{1}$ Abbreviations used in this paper: DFP, diisopropylfluorophosphate; FMLP, $N$-formyl-methionyl-leucyl-phenylalanine; PMN, blood polymorphonuclear leukocytes; and SBTI, soybean trypsin inhibitor.
} 
PMN, using cell aggregation and oxygen consumption as criteria for neutrophil activation.

\section{METHODS}

Materials. Prekallikrein, Factor XII fragments, and Factor XIa were purified to homogeneity as described elsewhere (5-7). Prekallikrein was activated to kallikrein using Factor XII fragments (5), which were not removed after activation. Thus kallikrein $(1 \mathrm{U} / \mathrm{ml}$ or $0.45 \mu \mathrm{M})$ contained $4.5 \mathrm{nM}$ Factor XII fragments. For kallikrein inactivation, kallikrein (4.54 $\mu \mathrm{M})$ was completely inactivated by soybean trypsin inhibitor (SBTI) (0.25 mM) or diisopropylfluorophosphate (DFP) (0.01 $M)$. After inactivation of kallikrein by SBTI, the excess inhibitor was not removed. In contrast, after kallikrein inactivation by DFP, the resulting preparation was extensively dialyzed to iemove any excess DFP. Purified human thrombin was a gift from J. W. Fenton II. Plasminogen purified by affinity chromatography (8) was activated to plasmin by urokinase (Hypolab S. A., Denens, Switzerland) at a 1:100 urokinase/plasminogen molar ratio. Bovine pancreatic trypsin and chymotrypsin, porcine pancreatic elastase, SBTI, DFP, $N$-formyl-methionyl-leucyl-phenylalanine (FMLP), and zymosan (Sigma Chemical Co., St. Louis, MO); bradykinin (Bachem Feinchemikalien AG, Bubendorf, Switzerland) and antiserum to human C5 (Atlantic Antibodies, Scarborough, ME) were purchased from the designated supplier. All other reagents used were reagent grade. Normal human serum was activated with zymosan as described (9).

$P M N$ isolation. $\mathrm{PMN}$ in $>98 \%$ purity with $<1$ platelet/ 1,000 cells were isolated from ADP-treated heparinized venous blood by dextran sedimentation and Ficoll-Hypaque gradient centrifugation (10). The cells were washed four times. For cell aggregation, purified PMN were suspended in phosphate-buffered saline, $\mathrm{pH} 7.4$, containing $5 \mathrm{mM}$ glucose (10). For oxygen uptake determination, purified PMN were suspended in Krebs-Ringer phosphate, pH 7.4.

$P M I N$ aggregation. Aggregometry was performed as a moditication (10) of the method described by Craddock et al. (11) in a standard platelet aggregometer (Payton Associates, Inc., model $300 \mathrm{~B}$ ) (10). To a silicone-coated cuvette containing a Teflon stir bar revolving at $900 \mathrm{rpm}, 0.45 \mathrm{ml}$ of a suspension containing $1.5 \times 10^{7} \mathrm{PMN} / \mathrm{ml}$ was added, along with the addition of $\mathrm{Ca}^{2+}(1.5 \mathrm{mM})$ and $\mathrm{Mg}^{2+}(1.5$ $\mathrm{mM})$. After a 2-min delay to allow warming of the cells to $37^{\circ} \mathrm{C}, 50 \mu \mathrm{l}$ of the aggregant was added, and the resulting changes in light transmission were recorded at $\Delta \mathrm{T}$. To provide the necessary amplification for a well defined aggregation wave, the aggregometer-recorder system was calibrated with a suspension containing $0.5-0.75 \times 10^{7}$ $\mathrm{PMN} / \mathrm{ml}$.

Oxygen consumption. Oxygen consumption was measured by the use of an oxygen electrode (model 53, Yellow Springs Instrument Co., Yellow Springs, $\mathrm{OH}$ ). A suspension of $10^{7} \mathrm{PMN}$ in $2.9 \mathrm{ml}$ of Krebs-Ringer-phosphate solution was placed in the reaction vessel. After 5 -min incubation at $37^{\circ} \mathrm{C}$ in the presence of $\mathrm{NaN}_{3}(1 \mathrm{mM}), 0.1 \mathrm{ml}$ of the stimulant solution was added. Oxygen consumption was recorded for $10 \mathrm{~min}$.

Statistical method. Results were expressed as mean \pm 1 SD. The significance of differences between means was assessed by unpaired Student's $t$ tests.

\section{RESULTS}

Purified human plasma kallikrein (final concentration $0.4-0.6 \mathrm{U} / \mathrm{ml}$ or $0.18-0.27 \mu \mathrm{M}$ ) aggregated blood PMN provided $\mathrm{Ca}^{2+}(1.5 \mathrm{mM})$ and $\mathrm{Mg}^{2+}(1.5 \mathrm{mM})$ were present during the reaction (Fig. 1A). Kallikrein-induced PMN aggregation was confirmed by phase microscopy. In contrast, no aggregation was observed when PMN were incubated with prekallikrein $(0.6 \mathrm{U} / \mathrm{ml}$ or 0.27 $\mu \mathrm{M})$, or with kallikrein $(0.6 \mathrm{U} / \mathrm{ml}$ or $0.27 \mu \mathrm{M})$ that had been previously inactivated by SBTI or DFP (Fig. 1A, d). Similarly, Factor XII active fragments $(0.023 \mu \mathrm{M})$, Factor XIa $(0.6 \mathrm{U} / \mathrm{ml}$ or $0.015 \mu \mathrm{M})$, thrombin $(1.6$ $\mu \mathrm{M})$, plasmin $(2 \mu \mathrm{M})$, and bradykinin $(1 \mu \mathrm{M})$ failed to aggregate PMN (Fig. 1A, d). Additional experiments revealed that porcine pancreatic elastase $(2 \mu \mathrm{M})$ or bovine pancreatic chymotrypsin $(2 \mu \mathrm{M})$ did not aggregate PMN (Fig. 1B, b), but that aggregation was observed when PMN were exposed to bovine pancreatic trypsin $(2 \mu \mathrm{M})(\mathrm{Fig}$. 1B, a). This response was absent when PMN were exposed to trypsin that had been previously inactivated by SBTI (Fig. 1B, b).

Quantitation of PMN aggregation indicated that significant responses were observed with kallikrein concentrations ranging from 0.4 to $0.6 \mathrm{U} / \mathrm{ml}$ or 0.18 to $0.27 \mu \mathrm{M}$ (Table I). For example, the mean response observed with $0.5 \mathrm{U} / \mathrm{ml}$ or $0.23 \mu \mathrm{M}$ kallikrein was almost identical to the mean response observed with an optimal concentration $(0.2 \mu \mathrm{M})$ of FMLP $(41.3 \pm 3.2 \mathrm{vs}$.
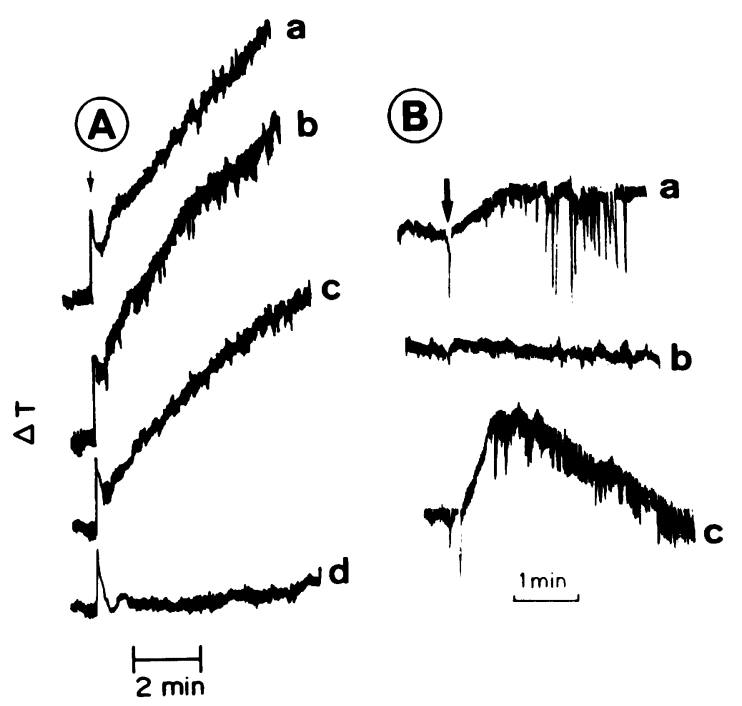

Figure: 1 PMN aggregation. (A) The various aggregants used included plasma kallikrein, $0.6 \mathrm{U} / \mathrm{ml}$ or $0.27 \mu \mathrm{M}$ (a); kallikrein, $0.5 \mathrm{U} / \mathrm{ml}$ or $0.23 \mu \mathrm{M}$ (b); kallikrein, $0.4 \mathrm{U} / \mathrm{ml}$ or $0.18 \mu \mathrm{M}$ (c); kallikrein, $0.6 \mathrm{U} / \mathrm{ml}$ or $0.27 \mu \mathrm{M}$, in the absence of divalent cations (d); Factor XII active fragments, 0.023 $\mu \mathrm{M}$ (d); Factor XIa, $0.6 \mathrm{U} / \mathrm{ml}$ or $0.015 \mu \mathrm{M}$ (d); thrombin, $1.6 \mu \mathrm{M}(\mathrm{d})$; plasmin, $2 \mu \mathrm{M}(\mathrm{d})$; bradykinin, $1 \mu \mathrm{M}(\mathrm{d})$; and buffer control (d). Only one negative response is illustrated. (B) The various aggregants used included bovine pancreatic trypsin, $2 \mu \mathrm{M}$. (a); SBTI-inactivated bovine pancreatic trypsin, $2 \mu \mathrm{M}$ (b); bovine pancreatic chymotrypsin, $2 \mu \mathrm{M}$ (b); porcine pancreatic elastase, $2 \mu \mathrm{M}$ (b); buffer control (b); and FMLP, $25 \mathrm{nM}$ (c) 
TABLE I

Effect of Plasma Kallikrein on PMN Aggregation

\begin{tabular}{lcc}
\hline \multicolumn{1}{c}{ Treatment } & $\begin{array}{c}\text { No. of } \\
\text { experiments }\end{array}$ & $\begin{array}{c}\text { Aggregation } \\
\text { response }\end{array}$ \\
\hline Control & 6 & $10.8 \pm 0.6$ \\
Kallikrein $(0.6 \mathrm{U} / \mathrm{ml}$ or $0.27 \mu \mathrm{M})$ & 4 & $55.9 \pm 1.6$ \\
Kallikrein $(0.5 \mathrm{U} / \mathrm{ml}$ or $0.23 \mu \mathrm{M})$ & 3 & $41.3 \pm 3.2$ \\
Kallikrein $(0.4 \mathrm{U} / \mathrm{ml}$ or $0.18 \mu \mathrm{M})$ & 4 & $31.8 \pm 1.0$ \\
FMLP $(0.2 \mu \mathrm{M})$ & 4 & $44.5 \pm 4.1$ \\
Kallikrein $(0.5 \mathrm{U} / \mathrm{ml}$ or $0.23 \mu \mathrm{M})$ & & \\
$\quad$ and goat antihuman $\mathrm{C5}$ & 3 & $37.3 \pm 2.4$ \\
\hline
\end{tabular}

- Quantitation of PMN aggregation during the initial 3 min was made using a Leitz compensating optical polar planimeter (E. Leitz, Inc., Rockleigh, NJ). Results are expressed in $\mathrm{cm}^{2} \pm 1$ SD.

45.5 $\pm 4.1, P>0.1$ ) (Table I). However, when PMN were incubated with lower concentrations of kallikrein ( $\leq 0.3 \mathrm{U} / \mathrm{ml}$ or $\leq 0.14 \mu \mathrm{M}$ ), no aggregation was observed, contrasting with significant responses to FMLP observed with tripeptide concentrations as low as 0.002 $\mu \mathrm{M}$ (not shown). PMN response to kallikrein and to trypsin were also compared, using the response to FMLP as a standard. Trypsin-induced PMN aggregation was of lesser magnitude than kallikrein-induced PMN aggregation, because the response observed with $2 \mu \mathrm{M}$ trypsin (Fig. 1B, a) was smaller than the response observed with $0.025 \mu \mathrm{M}$ FMLP (Fig. 1B, c).

To exclude the possibility of the participation of C5derived peptides in kallikrein-induced PMN aggregation, kallikrein was preincubated with an antiserum to C5. This treatment abrogated PMN aggregation by a 1:10 dilution of zymosan-activated $(32 \mathrm{mg} / \mathrm{ml})$ human serum (not shown). Identical aggregation responses to kallikrein $(0.5 \mathrm{U} / \mathrm{ml}$ or $0.23 \mu \mathrm{M})$ were observed, whether or not the enzyme had been exposed to the antiserum to $C 5(37.3 \pm 2.4$ vs. $41.3 \pm 3.2, P$ $>0.1$ ) (Table I).

For assessment of whether the interaction between kallikrein and PMN was associated with an increase in PMN oxidative metabolism, PMN were exposed to various concentrations of kallikrein and the oxygen consumption was determined. A 4.4-5.8-fold increase in oxygen consumption was observed when PMN were incubated with kallikrein concentrations ranging from 0.4 to $0.6 \mathrm{U} / \mathrm{ml}$ or 0.18 to $0.27 \mu \mathrm{M}$ (Table II). For comparison, PMN exposed to $0.2 \mu \mathrm{M}$ FMLP increased their oxygen consumption by 6.2 times (Table II).

\section{DISCUSSION}

The results presented in this report support the conclusion that highly purified human plasma kallikrein is a specific and potent aggregant agent for human blood PMN, as well as increases their oxidative metabolism.
TABLE II

Effect of Plasma Kallikrein on PMN Oxygen Consumption ${ }^{\circ}$

\begin{tabular}{lc}
\hline \multicolumn{1}{c}{ Treatment } & fmol/min/PMN \\
\hline Control & 0.098 \\
FMLP $(0.2 \mu \mathrm{M})$ & 0.608 \\
Kallikrein $(0.4 \mathrm{U} / \mathrm{ml}$ or $0.18 \mu \mathrm{M})$ & 0.434 \\
Kallikrein $(0.5 \mathrm{U} / \mathrm{ml}$ or $0.23 \mu \mathrm{M})$ & 0.520 \\
Kallikrein $(0.6 \mathrm{U} / \mathrm{ml}$ or $0.27 \mu \mathrm{M})$ & 0.564 \\
\hline
\end{tabular}

- Results of duplicate experiments were averaged.

The specificity of kallikrein for aggregating PMN was established by experiments showing that no aggregation was observed when PMN were exposed to Factor XII active fragments [which we used for prekallikrein activation (5)], Factor XIa [which in early stages of our preparation copurifies with kallikrein (5)], thrombin [which aggregates blood platelets (12)], plasmin, chymotrypsin, or elastase (Fig. 1A, d). Only trypsin was found to aggregate PMN, but less efficiently than did kallikrein (Fig. 1B, Table I).

Active kallikrein was required for PMN aggregation because prekallikrein, or kallikrein that had been inactivated by DFP or SBTI, failed to induce any response (Fig. 1A, d). Similarly, trypsin that had been inactivated by SBTI did not aggregate the cells (Fig. 1B, b). The need for an active enzyme species for PMN aggregation strongly suggested that PMN were activated as a result of a proteolytic cleavage. Kallikrein as well as trypsin liberate bradykinin from high molecular weight kininogen (1). However, bradykinin was not responsible for PMN aggregation because this hypothesis was directly tested (Fig. 1A, d). C5-derived peptides aggregate human PMN (11). In addition, rabbit kallikrein has been shown to cleave rabbit $\mathrm{C5}$, thereby liberating chemotactic peptides (4). Thus, experiments were designed to determine if our kallikrein preparation contained C5-derived peptides, or if a significant amount of C5 was present on the surface of purified human PMN. The kallikrein preparation did not contain C5-derived peptides because no differences in PMN aggregation were observed, whether or not kallikrein had been preincubated with an antiserum to C5 (Table I). Moreover, it is unlikely that human PMN had significant surface-associated C5 because plasmin, which liberates chemotactic peptides from C5 (13), failed to aggregate the cells (Fig. 1A, d). Therefore, plasma kallikrein appears to be a direct aggregant agent for human PMN. Moreover, because similar responses are observed with optimal doses of FMLP (10) or with kallikrein concentration that may be generated in vivo (14), kallikrein is a potent aggregant agent for PMN.

The interaction between plasma kallikrein and PMN was associated with stimulation of the respiratory 
burst, as indicated by an increased oxygen uptake observed when the cells were exposed to the enzyme (Table II). A parallel observation was made by others (3), who showed that partially purified kallikrein increased both PMN aerobic glycolysis rate and hexose monophosphate shunt activity (3).

In experimental animals, activation of Factor XII, and thus plasma kallikrein generation, results in the development of acute leukostasis, mainly in the gallbladder wall and the pulmonary blood vessels (15). In man, neutropenia is often observed with diseases such as gram-negative septicemia or typhoid fever (16), which are known to be associated with prekallikrein activation (14). Kallikrein-induced PMN aggregation may be an important factor for the occurrence of neutropenia and leukostasis in conditions associated with activation of the contact phase system.

\section{ACKNOWLEDGMENTS}

Dr. Boxer completed his portion of the work while an Established Investigator of the American Heart Association.

This work was supported in part by National Institutes of Health grants HL-14217, HL-24365, and A I 16948, by a grant (3.432.0.78) from the Swiss National Science Foundation, as well as by a grant from the Riley Memorial Association and the Council for Tobacco Research.

\section{REFERENCES}

1. Kaplan, A. P. 1978. Initiation of the intrinsic coagulation and fibrinolytic pathways of man: the role of surfaces, Hageman factor, prekallikrein, high molecular weight kininogen, and factor XI. Prog. Hemostasis Thromb. 4: 127-175.

2. Kaplan, A. P., A. B. Kay, and K. F. Austen. 1972. A prealbumin activator of prekallikrein. III. Appearance of chemotactic activity for human neutrophils by the conversion of human prekallikrein to kallikrein. J. Exp. Med. 135: 81-97.

3. Goetzl, E. J., and K. F. Austen. 1974. Stimulation of human neutrophil leukocyte aerobic glucose metabolism by purified chemotactic factors. J. Clin. Invest . 53: 591599.

4. Wiggins, R. C., P. C. Giglas, and P. M. Henson. 1981.
Chemotactic activity generated from the fifth component of complement by plasma kallikrein of the rabbit. J. Exp. Med. 153: 1391-1404.

5. Scott, C. F., C. Y. Liu, and R. W. Colman. 1979. Human plasma prekallikrein: a rapid high-yield method for purification. Eur. J. Biochem. 100: 77-83.

6. Schapira, M., C. F. Scott, and R. W. Colman. 1981. Protection of human plasma kallikrein from inactivation by $\mathrm{Cl}$-inhibitor and other protease inhibitors. The role of high molecular weight kininogen. Biochemistry. 20: 2738-2743.

7. Scott, C. F., M. Schapira, H. L. James, A. B. Cohen, and R. W. Colman. 1982. The inactivation of factor XIa by plasma protease inhibitors. Predominant role of $\alpha_{1}$-protease inhibitor and protective effect of high molecular weight kininogen. J. Clin. Invest. 69: 844-852.

8. Deutsch, D. G., and E. T. Mertz. 1970. Plasminogen: purification from human plasma by affinity chromatography. Science (Wash., DC). 170: 1095-1096.

9. Hammerschmidt, D. E., T. K. Bowers, C. J. LammiKeefe, H. S. Jacob, and P. R. Craddock. 1980. Granulocyte aggregometry: a sensitive technique for the detection of C5a and complement activation. Blood. 55: 898-902.

10. Oseas, R. S., L. A. Boxer, C. Butterick, and R. L. Baehner. 1980. Differences in polymorphonuclear leukocyte aggregating responses among several species in response to chemotactic stimulation. J. Lab. Clin. Med. 96: 213221 .

11. Craddock, P. R., D. Hammerschmidt, J. G. White, A. P. Dalmasso, and H. S. Jacob. 1977. Complement (C5a)-induced granulocyte aggregation in vitro. J. Clin. Invest. 60: 260-264.

12. Weiss, H. J. 1975. Platelet physiology and abnormalities of platelet function. N. Engl. J. Med. 293: 531-541.

13. Goldstein, I. M., and H. D. Perez. 1980. Biologically active peptides derived from the fifth component of complement. Prog. Hemostasis Thromb. 5: 41-79.

14. Colman, R. W., and P. Y. Wong. 1979. Kallikrein-kinin system in pathologic conditions. In Handbook of Experimental Pharmacology. Vol. XXV Suppl. E. G. Erdös, editor. Springer-Verlag Berlin, Heidelberg, New York. 569-607.

15. Becker, C. G., T. Dubin, and F. Glenn. 1980. Induction of acute cholecystitis by activation of Factor XII. J. Exp. Med. 151: 81-90

16. Murdoch, J. M., and C. C. Smith. 1972. Infection. Clin. Haematol. 1: 619-644. 